\title{
EVALUATION OF A MURINe MODEl OF EXPERIMENTAL TRICHOMONIASIS
}

\author{
NOGAL RUIZ J.J., ESCARIO J.A., MARTINEZ DIAZ R.A. \& GOMEZ BARRIO A.*
}

\section{Summary :}

By using a reference strain of Trichomonas vaginalis and the intraperitoneal route for infecting animals, the influence of the strain of mice, the time observation and the inoculation doses were followed in order to standardize the optimal conditions for the evolution of experimental trichomoniasis. Our results suggest that the inoculation of $\mathrm{BALB} / \mathrm{c}$ mice with $10^{7}$ trichomonads and the semiquantitative assessment at day 15 postinfection of the grosspathologic changes in the abdominal cavity - peritoneum, spleen, pancreas, stomach and liver - as well as the presence of ascitic fluid and mortality, maybe a suitable laboratory model of trichomoniasis.

KEY WORDS : Trichomonas vaginalis, pathogenicity, mouse.
Résumé : Évaluation d'Un MODÈlE DE TRICHOMONIASIS EXPÉRIMENTAL CHEZ LA SOURIS

L'étude de l'activité pathogène de Trichomonas vaginalis a été abordée par l'observation des lésions provoquées expérimentalement sur des animaux de laboratoire. Nous avons employé la voie d'inoculation intrapéritonéale et une souche de référence de $\mathrm{T}$. vaginalis $(\mathrm{Cl}: \mathrm{NIH})$ pour établir les conditions liées à la souche de souris, au temps d'observation et à la dose inoculée les plus favorables pour l'évaluation d'un modèle de trichomoniasis expérimental. Les résultats ont montré que l'inoculation des souris de la souche BALB/C avec 107 trichomonas et l'évaluation semi-quantitative des lésions pathologiques provoquées dans la cavité abdominale, le péritoine, l'estomac, le pancréas, et dans le foie, ainsi que la présence d'ascite simple avec T. vaginalis, pourraient constituer un bon modèle expérimental de trichomoniasis.

MOTS CLÉS : Trichomonas vaginalis, pathogénicité, souris.

\section{INTRODUCTION}

\section{T} trichomoniasis is among the world's most common sexually transmitted diseases (Thomason and Gelbart, 1989). Its clinical manifestations vary from an asymptomatic infection to an acute vaginitis. The parasite, Trichomonas vaginalis, is a major cause of vaginitis, cervicitis and urethritis in women and may cause nongonococcal urethritis, prostatitis, and perhaps other lower genitourinary tract syndromes in men (Krieger et al., 1990). As another STDs, trichomoniasis could play a major role as a cofactor (Laga et al., 1993) in the transmission of HIV infection.

A single drug, metronidazole, is currently available for treating trichomoniasis. However, metronidazole-resistant strains have been isolated from unsuccessfully

\footnotetext{
* Departamento de Parasitología, Facultad de Farmacia, Universidad Complutense, Ciudad Universitaria s/n, 28040 Madrid, España. Correspondence: Gómez Barrio Alicia.

Tel : 913941817 - Fax : 913941815.
}

treated patients (Müller et al., 1988) and there are concerns over the mutagenicity and potential carcinogenicity of this drug (Lossick, 1990).

The great variability in the presentation and/or in the evolution of trichomoniasis as well as in its response to treatment, justify the need of an experimental model for determination of natural isolates pathogenicity and for pharmacological screening. After Schnitzer et al. (1950) infected successful mice with T. vaginalis, several investigators have used the laboratory mouse in studies of host-parasite interactions, virulence assays and drug tests. Among the disease-producing infections in these experimental hosts, the intraperitoneal inoculation (Teras \& Roigas, 1966; Gobert et al., 1969, 1971 ) is recognized to cause a fibropurulent peritonitis with abscesses and necrotic foci in abdominal organs and production of ascitic fluid. The severity of the infection, although dependent on the responsiveness of the individual animal, reflects the inherent virulence of the inoculated strain (Kulda, 1990).

The present work was performed as an attempt of standardization of an experimental model of future application in studies of pathogenicity and chemotherapy of $T$. vaginalis. The employment of suitable mouse 
strains, the dose of inocula that ensures sufficiently high infection rates and allows differential development of lesions characteristic of an individual trichomonad strain are the key factors in the pathogenicity assays. Also, if the model is thought to its extensive use in pharmacological screening, the duration of the experiment is another factor to have in mind. These three parameters: strain of mice, inoculum and observation time were evaluated in our experiences.

\section{MATERIALS AND METHODS}

\section{ORGANISM AND CULTURE}

vaginalis strain $\mathrm{C} 1 \mathrm{NIH}$ isolated from human adult female with acute vaginitis was obtained from the American Type Culture Collection (reference no. 30001). Previous experiences using the ATCC strain named JH31A no. 4 for infecting NMRI mice (Escario et al., 1995) and BALB/c mice (data not published) showed its scarce experimental pathogenicity. The clinical findings of trichomoniasis caused by C1:NIH strain indicates its greater natural pathogenicity and it seems to be more appropriate to evaluate a murine model of experimental trichomoniasis. Parasites are maintained in our laboratory by criopreservation in liquid nitrogen. For infecting animals, organisms were growth at $37{ }^{\circ} \mathrm{C}$ with $5 \% \mathrm{CO}_{2}$ in Tryticase-Yeast extract-Maltose (TYM) medium, pH 6.2, supplemented with $10 \%$ heat inactivated horse serum, penicillin $\mathrm{G}(100 \mathrm{IU} / \mathrm{ml})$ and streptomycin $(100 \mathrm{mg} / \mathrm{ml})$ (Diamond, 1957). After two or three reseedings in fresh culture medium, enough number of parasites was obtained to the experimental infections of mice.

\section{ANIMALS}

$\mathrm{BALB} / \mathrm{c}$ and C57BI10 mice from Iffa Credo (Criffa, Spain) and NMRI and CD-1 mice, bred under standard conditions in our laboratory were used for experimental infections. All animals were maintained in a temperature and humidity controlled environment with a $12 \mathrm{~h}$ light/dark cycle and given water and food ad libitum. Both inbred and outbred mice weighed 20$25 \mathrm{~g}$ at the beginning of the experiments.

\section{EXPERIMENTAL DESIGN}

The first series of experiences was performed to find the strain of mice most susceptible to the infection with $T$. vaginalis. To inoculate the animals, logarithmicgrowth phase parasites from axenic cultures resuspended in fresh medium were administered in a single dose. Groups of 20 mice of each strain were injected intraperitoneally with $10^{7}$ trichomonads. Half of the animals were sacrified at day 15 postinfection and the other half at day 30 postinfection in order to follow the course of infection.

In a second step, an experiment was performed in order to determine the optimum inoculum. For this purpose, 30 mice of the most susceptible strain selected previously were divided into three groups and injected intraperitoneally with $10^{6}, 5 \times 10^{6}$ and $10^{7}$ trichomonads.

\section{PATHOGENICITY DETERMINATION}

An index of pathogenicity (PI) was determined following the criteria recommended by Toyos (1974). Briefly, mortality, ascites, and the gross damage produced to the peritoneum, spleen, pancreas and stomach, and to the visceral (distal) and diaphragmatic (proximal) liver faces were rating according to Table I. Both the mice that succumbed to the infection and those killed after the observation time were examined at necropsy for the presence of trichomonads and for gross-pathologic changes in the abdominal cavity. The PI was then calculated as the arithmetic mean of the values for each parameter. As maximum value is 100 , results can be expressed as percentages.

\section{STATISTICAL ANALYSIS}

Statistical analysis was performed using the nonparametric Mann-Whitney U and Kruskal-Wallis H tests. The first one allows assume that two independent samples come from populations having the same distribution. To test for differences among more than two independent samples, the Kruskal-Wallis one way analysis of variance was used. A probability $p<0.05$ was considered indicative of statistical significance.

\section{RESULTS}

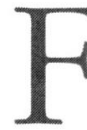
ig. 1 shows the pathogenicity indices of T. vaginalis in each of the four mouse strains. Two determinations of pathogenicity, at days 15 and 30 postinfection, were made in every experiment. Analysis of variance by Kruskal-Wallis $\mathrm{H}$ test indicated that the four strains of mice show statistically different susceptibility to parasite, both at 15 and 30 days postinfection. In the Mann-Whitney $U$ analyses by pairs of strains, there were a statistically significant difference for $p<0.01$ among PI of BALBc strain and PIs of NMRI, CD-1 and C57BL/10J, both at 15 and 30 days postinfection. By contrast, Mann-Whitney's U values for the pairs NMRI/CD-1, NMRI/C57BL/10J and CD$1 / \mathrm{C} 57 \mathrm{BL} / 10 \mathrm{~J}$ showed no difference $(p<0.05)$ between the PIs compared. Therefore, BALBc/mice were the most susceptible to $T$. vaginalis, being the PIs 
Pathologic manifestations

Values assigned

Mortality

(Days p.i.)

$3^{\circ}$

$4^{\circ}$

$5^{\circ}$

Every delay day

$>10^{\circ}$

Ascites

$<1 \mathrm{ml}$

1-2 $\mathrm{ml}$

$>2 \mathrm{ml}$

Peritoneum

$1-3 \mathrm{SN}$

Multiple SN and/or N1

Multiple N1 and/or N2

MN affecting pelvis

$\mathrm{N}$ affecting intestine and kidneys

Spleen, Pancreas and Stomach

1-3 SN and/or splenomegaly

Multiple SN and/or N1

N2

$\mathrm{N} 3$ affecting more than 1 organ

N4

$\mathrm{N} 5$ affecting liver and intestine

Visceral liver side

1-3 SN

N1

N2

N3

N4

Diaphragmatic liver side

1-3 SN and/or colour changes

N1

N2

N3

N4

N5

SN: Single necrosis; N1: Necrosis of 3-5 mm diameter, N2: Necrosis of 5-8 mm. MN: Multiple Necrosis; N: Necrosis; N3: Necrosis of 8$10 \mathrm{~mm}$; N4: Necrosis of 10-15 mm; N5: Necrosis of more than $15 \mathrm{~mm}$ of affecting the most organ surface.

Table I. - Rating of pathological manifestations in mice infected by the intraperitoneal route with Trichomonas vaginalis (Following Toyos J.M.: Patogenia experimental de Trichomonas vaginalis Donné 1836, en el ratón (Mus musculus). Anales de la Facultad de Veterinaria de León, 1974, 20, 25-90).

determined at days 15 (37) and 30 (41.5) after infection statistically greater than PIs calculated for the other strains of mice in both determinations of pathogenicity.

By contrast, there was no difference $(p>0.05)$ among Mann-Whitney's U values for the pairs comparison between the PIs at days 15 and 30 after infection in every strain of mice.
After mice strain and duration of infection were selected, a subsequent experiment conducted to know the minimal inoculum necessary to be establishment of the infection was performed by inoculation of BALB/c mice with three different inocula (Fig. 2). When statistical analyses was performed, we showed that variations of inoculation doses ranging between $10^{6}$ and $5 \times 10^{6}$ cells do no affect substantially the size of the resulting lesions; however, the employment of a parasite number of $10^{7}$ results in a PI statistically different $(p<0.01)$.

Finally, PI determined in BALB/c mice in the first experiment (Fig. 1d) at day 15 after infection and PI determined for the same mice in the last experiment using different inocula (Fig. 2) were compared by Mann Whitney U test. No differences $(p>0.05)$ were seen between the two PI values from similar experiments.

\section{DISCUSSION}

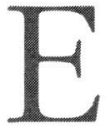

xperimental infections produced by inoculation of $T$. vaginalis into various extravaginal sites have been extensively studied in mice (Kulda, 1990), but results are sometimes controversial. Discrepancies between the results of various pathogenicity assays derive from differences in the strains of mice and parasites, size and route of inoculation and evaluation procedures.

In our series of assays directed to know the susceptibility of mice to the reference strain of $T$. vaginalis, $\mathrm{BALB} / \mathrm{c}$ mice were found to be the most susceptible. Although experimental infection of NMRI mice allows to find differences among T. vaginalis isolates (Escario et al., 1995), the evolution of experimental trichomoniasis can be improved by using $\mathrm{BALB} / \mathrm{c}$ mice. Moreover, $\mathrm{JH} 31 \mathrm{~A} T$. vaginalis ATCC strain then used by the authors is far from being the most adequate strain to standardize a murine model of experimental trichomoniasis.

Landolfo et al. (1979) found certain differences in the susceptibility of different inbred strain of mice to intraperitoneal infection with $8 \times 10^{5}$ cells of $T$. vaginalis strain isolated from a patient suffering acute trichomoniasis. Although the pathogenicity levels determined by these authors are clearly higher than those obtained by us, BALB/c mice were also the most susceptible to parasite. Such variations in inherent pathogenicity levels have been reported in earlier studies (Honigberg, 1961; Ivey and Hall, 1964) and are a consequence of differences in biological materials and experimental design.

The relative virulence of a strain of $T$. vaginalis for murine and human hosts has been extensively dis- 

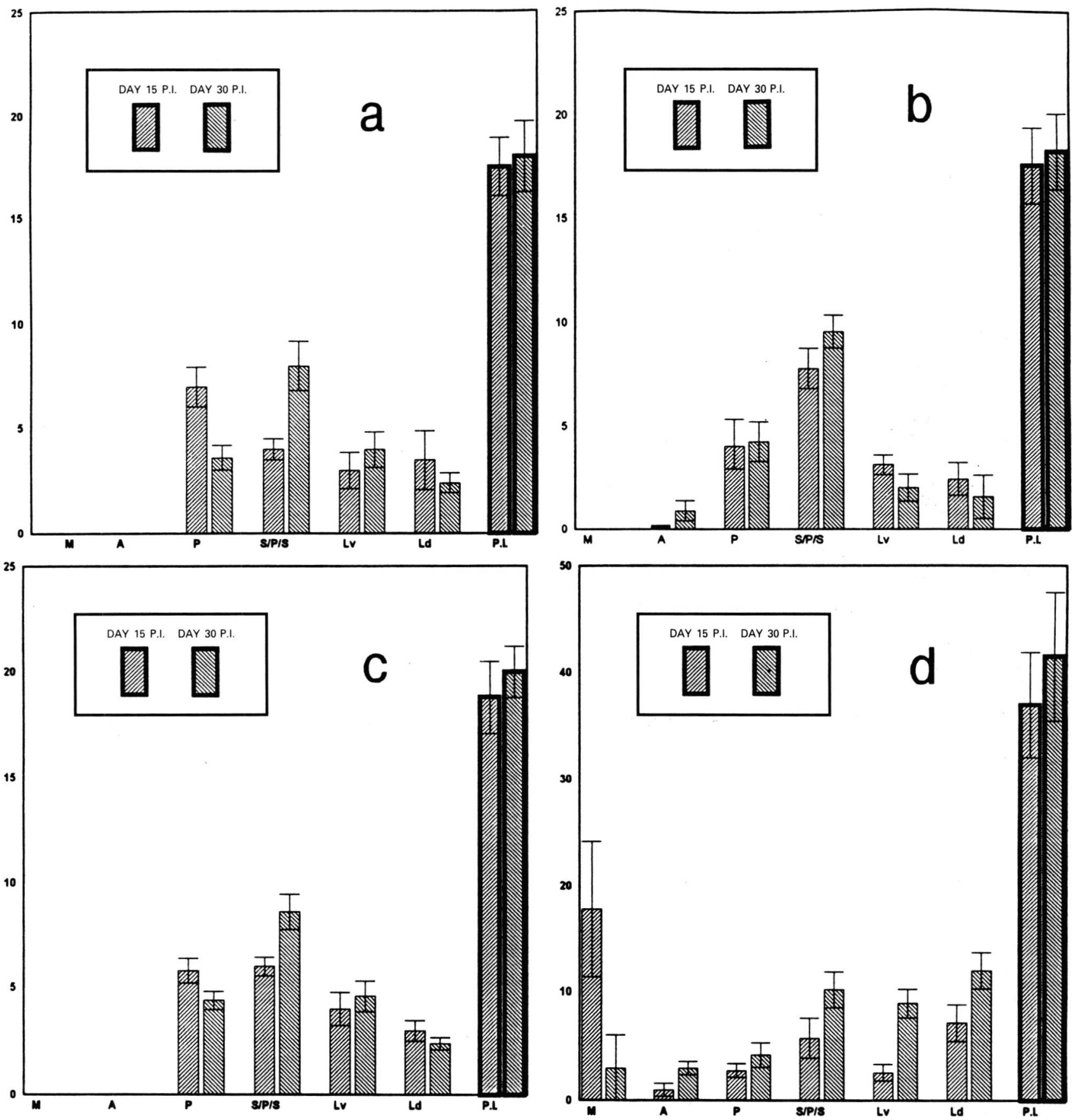

Fig. 1. - Values assigned to the pathologic manifestations and mean pathogenicity indices in mice after 15 and 30 days of the infection with $10^{7}$ Trichomonas vaginalis, as expressed by the arithmetic means and the standard errors.

$a$ : NMRI mice; $b$ : CD-1 mice; $c$ : $\mathrm{C} 57 \mathrm{BL} / 10 \mathrm{~J}$ mice; $d: \mathrm{BALB} / \mathrm{c}$ mice. M: mortality; A: ascites; $\mathrm{P}$ : peritoneum; $\mathrm{S} / \mathrm{P} / \mathrm{S}:$ spleen/pancreas/stomach; Lv: liver (visceral); Ld: liver (diaphragmatic); P.I.: pathogenicity index. 


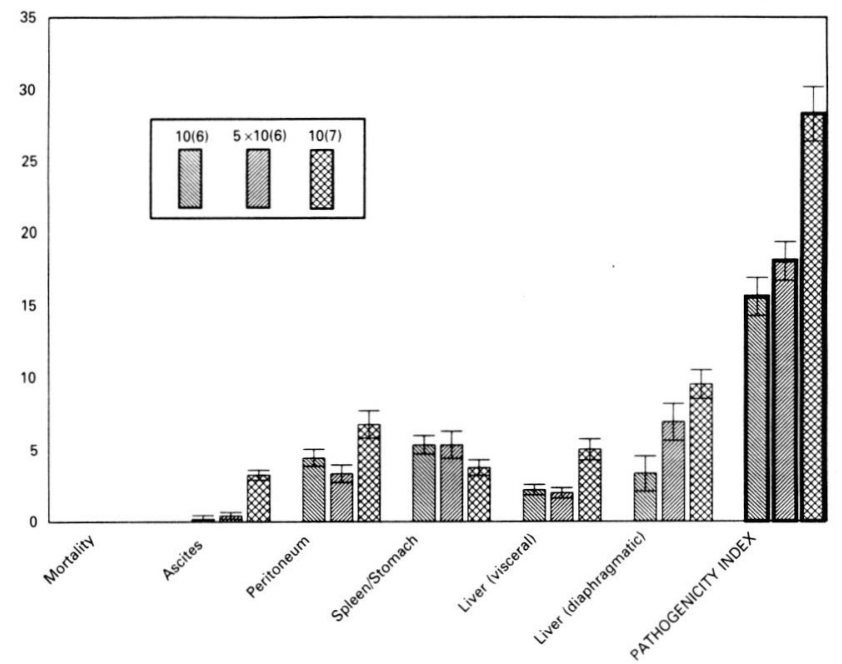

Fig. 2. - Values assigned to the pathologic manifestations and mean pathogenicity indices in BALB/c mice after 15 days of the infection with $1.000 .000,5.000 .000$ and 10.000 .000 of Trichomonas vaginalis, as expressed by the arithmetic means and the standard errors.

cussed and is far from perfect. Nevertheless, in an attempt to correlate results of intraperitoneal mouse assays with clinical findings recorded from patients, Teras and Roigas (1966) found that the occurrence of strains with higher virulence for mice was considerably lower in patients with latent and chronic disease than in those with acute and subacute trichomoniasis. According to estonian workers, Kulda (1990) compared the virulence of 25 fresh $T$. vaginalis isolates by subcutaneous, intraperitoneal and mortality assays and he found that the strains with the highest virulence for mice fitted into the group of isolates that caused the most severe lesions in humans. In a previous paper (Escario et al., 1995), a correlation between experimental pathogenicity in vivo with adherence to HeLa cell cultures, but not with in vitro citotoxicity, could be established. Unfortunately, we had not data about clinical findings of the T. vaginalis isolates to compare experimental and natural pathogenicity. The observation period for pathogenicity determination has been also subject of discrepancies. So, while some authors propose 11 days (Teras \& Roigas, 1966; Toyos, 1974) others (Cavier et al., 1972; Kulda, 1990) recommend a observation time about three weeks. When we compare the indices of pathogenicity at 15 and 30 days after infection with every of the four mice strains, no significant statistical differences were found. If the model maybe used for pharmacological screening, its duration is one of the factors to have in mind. Further experiences with some reference drugs as metronidazole must be performed in order to know the application of this murine model to pharmacological screening, but the present results seem indicate that the observation period longer, that is to say, the activity determination at day 30 after infection, apparently does not offer any advantage. The most variable data by comparing the results obtained at both observation times can be seen for the most susceptible mice $\mathrm{BALB} / \mathrm{c}$. In the group of mice for pathogenicity determination at day 15 after infection, the mortality value is the highest, consequence of the death of the animals within the first days after infection. In the batch of mice examined at day 30 after infection, animals die later, so mortality value is lesser, according to Table I. However, the survivor animals developed gross-pathologic changes considerably larger. After all, pathogenicity indices do not differ statistically.

With respect to the assays of different inocula, variations of inoculation doses ranging between $10^{6}$ and $5 \times 10^{6}$ do not affect statistically the gross-pathologic changes observed in the abdominal cavity, but the highest doses $\left(10^{7}\right)$ ensure a statistically different infection rate and allow the best assessment of pathologic manifestations. Differences in pathogenicity indices related to the size of inoculum have been reported in subcutaneous infection of mice. According to Honigberg's method (Honigberg, 1961; Frost \& Honigberg, 1962), the subcutaneous lesions can be consistently produced by inoculation of mice with 8 to $9 \times 10^{5}$ trichomonads, but the employment of much higher parasite numbers ( $\geq 2 \times 10^{6}$ cells) tends to impair the sensitivity and usefulness of the virulence assays.

Although numerous data are available on animal experiments with trichomonads always the comparison of the results from different procedures must be made with caution. Most of the reports mentioned above use not well characterized natural isolates of the parasite, increasing so the variability of the host-parasite interactions. The main advantage of the model we propose is the use of a reference strain of $T$. vaginalis, avoiding so the variability inherent to the parasite. This allows us to approach the study of another variables, such as mouse strain, inoculum dose and observation time. In our experimental conditions, we can conclude that the experimental infection of BALB/C mice by the intraperitoneal route with $10^{7}$ trichomonads and the evaluation of pathogenicity on day 15 p.i. may be a suitable experimental model.

\section{REFERENCES}

Cavier R.E., Gobert J.G. \& Savel J. Application d'une méthode d'infestation intrapéritonéale de la souris par Trichomonas vaginalis à l'étude pharmacologique des trichomonacides. Annales Pharmaceutiques Françaises, 1972, 30, 637-642.

DiAmOND L.S. The establishment of various trichomonads of animals and man in axenic cultures. Journal of Parasito$\log y, 1957,43,488-490$. 
Escario J.A., Gomez Barrio A. \& Martinez Fernandez A.R. The relationship of experimental pathogenicity in vivo with in vitro cytoadherence and cytotoxicity of 6 different isolates of Trichomonas vaginalis. International Journal for Parasitology, 1995, 25, 999-1000.

Frost J.K. \& Honiberg B.M. Comparative pathogenicity of Trichomonas vaginalis and Trichomonas gallinae for mice. II. Histopathology of subcutaneous lesions. Journal of Parasitology, 1962, 48, 898-918.

Gobert J.G., Georges P., Savel J., Genet P. \& Piette M. Étude de l'endoparasitisme expérimental de Trichomonas vaginalis chez la souris. II. Étude cytologique et histologique. Annales de Parasitologie Humaine et Comparée, 1969, 44, 687-696.

Gobert J.G., Truchet M. \& Savel J. Étude de l'endoparasitisme expérimental de Trichomonas vaginalis chez la souris. IV. Étude histochimique des lésions chez les animaux parasites. Annales de Parasitologie Humaine et Comparée, 1971, 46, 511-522.

HonigBerg B.M. Comparative pathogenicity of Trichomonas vaginalis and Trichomonas gallinae to mice. I: Gross pathology, quantitative evaluation of virulence and some factors affecting pathogenicity. Journal of Parasitology, 1961, 47, 545-571.

IVEY M.H. \& Hal. D.G. Virulence of different strains of Trichomonas vaginalis in the mouse. American Journal of Tropical Medicine and Hygiene, 1964, 13, 16-19.

Krieger J.N., Wolner-Hanssen P., Stevens C.A. \& Holmes K. Characteristics of Trichomonas vaginalis isolates from women with and without Colpitis macularis. Journal of Infectious Diseases, 1990, 161, 307-311.

KulDA J. Employment of experimental animals in studies of Trichomonas vaginalis infection. In: Trichomonads Parasitic in Humans. Honigberg B.M. (ed.), Springer-Verlag, New York, 1990, 112-154.

laga M., Manoka A., Kivuvu M., Malele B., Tuliza M., Nzila N., Goeman J., Behets F., Batter V., Alary M., HeyWARD W.L., RYder R.W. \& PIOT P. Non-ulcerative sexually transmitted diseases (STD) as risk factors for HIV-1 transmission in women: results from cohort study. AIDS, 1993 , 7, 95-102.

Landolfo S., Martinotti M.G., Martinetto P. \& Forni G. Genetic control of Trichomonas vaginalis infection. I. Resistance or susceptibility among different mouse strains. Boll Ist Sieroter Milan, 1979, 58, 48-51.

Lossick J.G. Therapy of urogenital trichomoniasis. In: Trichomonads Parasitic in Humans. Honigberg B.M. (ed.), Springer-Verlag, New York, 1990, 324-341.

Müller M., Lossick J.G. \& Gorell. T.E. In vitro susceptibility of Trichomonas vaginalis to metronidazole and treatment outcome in vaginal trichomoniasis. Sexually Transmitted Diseases, 1988, 15, 17-24.

Schnitzer R.J., Kelly D.R. \& Lerwant B. Experimental studies on trichomoniasis. I. The pathogenicity of trichomonad species for mice. Journal of Parasitology, 1950, 36, 343349.

Teras J. \& Roigas E. Characteristics of the pathomorphological reaction in cases of experimental infection with Tri- chomonas vaginalis. Wiadomosci Parazytologizne, 1966, 12, 161-172.

ThOmason J.L. \& Gelbart S.M. Trichomonas vaginalis. Obstetrics and Gynecology, 1989, 60, 30-34.

Toyos J.M. Patogenia experimental de Trichomonas vaginalis Donné 1836 en el ratón (Mus musculus). Anales de la Facultad de Veterinaria de León, 1974, 20, 35-90.

Reçu le 19 octobre 1996 Accepté le 3 février 1997 